\title{
THE KEHLER MANAGEMENT SYSTEM: A HOLISTIC FRAMEWORK FOR THE ADMINISTRATION OF MUNICIPALITIES
}

\author{
Roland Böhmer ${ }^{1}$, Uwe Busbach-Richard ${ }^{2}$, Britta Kiese ${ }^{3}$

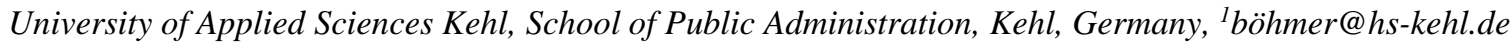 \\ ²busbach@hs-kehl.de, ${ }^{3}$ kiesel@hs-kehl.de
}

\begin{abstract}
Research purpose. Especially against the background of a globalised world, municipal managers are confronted with increasingly complex tasks. Furthermore, the range of tasks of a municipality and its stakeholders are very heterogeneous. While repetitive work processes are basically characterised by a clear starting position and objectives and the resources required to achieve these objectives are known and available, these manageable prerequisites are usually not present in complex public administration systems. The transfer of purely management ratio-based approaches from the business management sector is difficult for public administration, since not profit but the common good is the prioritized target. Municipal managers need a holistic approach that addresses the municipal council, the population, companies, administrative organization and budget management in order to be able to control municipalities within a diagnostic framework.
\end{abstract}

Design/Methodology/Approach. First of all, a brief insight into the history of the new municipal budget law in Germany is given. The aim of the budget law is to reform the budget and accounting system, but above all, to strengthen municipal control through goal orientation. After an overview of the current diagnostic frameworks, it becomes clear that a holistic approach is missing. To develop such a framework, success factors for municipal control are identified. These are then combined into success clusters to create a more manageable, holistic structure for implementation - the Kehler Management System (KMS). A survey and two case studies, which were conducted within two years in the municipality of Ottersweier, empirically prove the practical relevance of the KMS approach.

Findings. 36 success factors were identified, which were structured into six success clusters. One success cluster addresses the trusting cooperation between politics and administration (in short: politics and administration). A culture of leadership and cooperation within the administration is another cluster of success (in short: culture of leadership and cooperation). Sustainable human resources management forms the third cluster of success factors (in short: human resources management). A further cluster could be identified in the strategic area (in short: strategy). A fifth cluster of success relates to the conversion to a modern budget and accounting system, which considers resource consumption (in short: municipal accrual accounting as a control instrument). The last success cluster addresses changes in the administrative environment (in short: learning organization). The six success clusters are not independent, however, these have a causal order. The municipal accrual accounting as a control instrument and the integration of the strategy are fundamental for the other four success clusters, which address the implementation of the reform process.

Originality/Value/Practical implications. In 2015, the framework of the KMS was evaluated in a survey of 115 municipalities with up to 50,000 inhabitants and was considered coherent and helpful by the municipal executives. In individual communities like Ottersweier, detailed diagnostic analyses based on the Kehler Management System were conducted with various internal stakeholders, which led to strategy development, resource-oriented budget management, operational implementation, and a continuous improvement process. However, only the internal view of the municipal administration is currently addressed. In an extension of the KMS, further research aims at integrating the external view of citizens and companies into the framework.

Keywords: Performance analyses of municipalities; resource-oriented budget in municipalities

JEL codes: $\mathrm{H} 72 ; \mathrm{H} 83$ 


\section{Introduction}

In 2003, the interior ministers of the German states decided on a reform of local budget legislation to overcome information and governance deficits in traditional cameralistics. Unlike in most Anglophone countries, the local government in Germany has large areas of competence that directly affect the citizens' wellbeing. Therefore, reforms that have been implemented since the 1990s in many countries under the name 'New Public Management' from the national level downwards have been particularly well received in German municipalities as the lowest level of government. In Baden-Württemberg, the New Municipal Budget Law (in German Neues Kommunales Haushaltsrecht; abbreviation - NKHR) came into force in 2009. It is intended to fundamentally change municipal control, supported by the introduction of municipal accrual accounting and new output-based budgets. The term municipal control (management) means the management activities of planning, decision making, execution and control that are used to gear a municipal administration towards specific objectives, taking into account the political, economic, social, technological and ecological framework conditions. At least two types of objectives can be distinguished: political and financial objectives.

The principle objectives are set by the constitutions of states. Baden-Württemberg's municipal constitution, for example, calls for orientation towards the common good of the residents of the municipality (for a reflection on policy making for the 'common good,' see Boston J. (2013)), the fulfilment of the tasks assigned by the federal and state governments, and economical and efficient budget management. In the municipal policy process, these normative objectives are concretized in terms of the current problems and opportunities and corresponding public products and services (output). The processes of setting objectives, selecting measures to achieve them, and choosing products and services and monitoring success can be more or less formalized or 'managed' - however, they take place in any case.

The state legislator wants to strengthen both sides, political and financial with the NKHR, that is, through formalization. The output structure of the budget and the specification of KPIs are intended to focus the political planning process and to keep the objectives in the minds of decisionmakers and service providers throughout the year. Meanwhile, accrual accounting enforces a transparent and sustainable budget management.

However, it is questionable how this new information is used for decision making in practice. For with a few exceptions, their use is neither prescribed nor predetermined. Even if objectives are written down, it remains open what role they play in the planning, decision making and evaluation processes. In other words, while the NKHR introduces useful instruments and procedures, these are not in themselves a guarantee of successful local governance.

Empirical studies do indeed draw a rather pessimistic picture of the implementation status, especially in small and medium-sized municipalities. 'There is a control gap,' a nationwide survey summarizes (Fischer \& Lasar 2014). Strategic targets are characterized by a horizon of several years, their overarching character and their impact orientation. Provided initial political will, the biggest problems arise rather in updating and implementing strategies between strategic and operational management than in strategy development itself.

Legal requirements are not enough to reach the objectives. Management approaches should focus less on defining and imposing formal structures and more on facilitating local institution-building processes (Leach \& Lowndes 2004).

\section{Literature review}

Concepts and frameworks for analysing and improving the performance of organizations and for measuring their performance have been available in business management for some time. Most private sector tools single out financial performance, most explicitly in the Shareholder Value approach. The first and best-known approach to seriously tackle this imbalance in business management was the Balanced Scorecard (BSC) with four dimensions, that is, customer, finance, learning and development, and process (Kaplan \& Norton, 1992). However, the implementation to private sector practice has been somewhat less successful, and the BSC can serve as a good example to explain why. One important 
reason for the low implementation success rate is that of behavioural performance factors (Manville, 2007), which can have a negative impact on the efficient execution of the performance management system, are too often ignored. Even though it is an improvement from purely financial KPIs, the causeand-effect relationships of the BSC focus strongly on the financial dimension. The results for the 'upstream' three dimensions aim to lead to performance improvement in the fourth, 'downstream' dimension, that is, the financial results. This concept clearly identifies finance as the endpoint of the BSC's performance management objectives. This viewpoint seems to contradict the multi-dimensional objectives of most public sector organizations and is even not sufficient for a holistic view to private sector practice.

A restructuring of the cause-and-effect relationships so that different dimensions and multiple objectives are in the focus of performance measurement seems necessary. Concerns about the existence, nature and verification of BSC-cause-effect relationships are discussed in the general BSC literature (e.g., Brignall, 2002; Nørreklit, 2003; Davis \& Albright, 2004; Bukh \& Malm, 2005; Malina et al., 2007), but with regard to the public sector, there is a research deficit as to whether the BSC can be considered a useful performance verification tool in this area of application.

Another problem is that the BSC is still private-sector oriented and has little weight on the involvement of service users, risk management or the need to work across organizational boundaries (Moullin, 2006). Moreover, public sector reforms have 'implications for social and political dimensions that are not taken into account in private sector frameworks' (Cordella \& Bonina, 2012).

One attempt at a KPI model that reflects the complexity of the municipal world better has been the Public Sector Scorecard (PSS) (Moullin, 2017). The PSS addresses seven perspectives. Leadership is seen as the basis for innovation and learning as well as people, partnerships and resources. Based on this, service delivery is developed, considering service users and stakeholders on the one hand and finances on the other. This leads to the achievement of the strategic performance targets, which must be defined at the beginning. PSS addresses the cultural level and the learning organization to a certain extent. However, the PPS lacks the cultural dimension of politics and administration and their different rationalities.

The Organizational Performance Management (OPM) approach was specially developed to evaluate municipal administration. The focus of OPM in municipalities is on the adaptability and complex interrelationships between the measurement and management of quality, productivity, innovation and profitability in terms of improving the performance of the whole organization. The role of performance management includes responsibility for behavioural, motivational and process improvements. This leads to five 'universal criteria' for OPM implementation: leadership commitment, strategy focused on performance objectives, stakeholder involvement, continuous monitoring, evaluation and feedback, and building a culture of performance in delivering high quality outputs and outcomes (Fryer et al., 2009). A normative approach to OPM identifies three areas to be addressed: Political-philosophical values and principles, scientific values and principles and managerial values and principles (Jessa \& Uys, 2013). However, questions of conceptual and operational interrelationships both between these three areas and the five 'universal criteria' mentioned above remain unanswered. Furthermore, the cultural level of cooperation between politics and administration and the trust necessary for this is only addressed to a limited extent.

Other performance measurement approaches were the EFQM model, adapted for the public sector in 1994, the Common Assessment Framework specifically developed for the public sector (Best, 1997), the performance measurement approach for developing nations of the World Bank (Cannon \& Fry, 1992) or the concept of public value (Moore, 1995).

To sum up, experience with the implementation of NPM have been around since the 1990s (Hood, 1991; Boston et al., 1996). For a comprehensive analysis of developments in New Zealand as the world's first mover in this field, see Yui and Gregory (2018). Due to serious criticism of the economization of the public sphere, the focus has been shifting from efficiency to effectiveness. All frameworks for the analysis of urban administrations mentioned above try to reflect this criticism but have in common that effectiveness and cooperation culture between politics and administration are only looked at in a limited way. 


\section{Research methodology}

The Kehler Management System (KMS) addresses effectiveness in a holistic and integrated way since it is open for different rationalities. Due to the diversity of numerous actors in a municipality - citizens, administrative leaders, politicians, companies and so on - different interests and world views are leading to different expectations and actions. Structural, personnel and cultural conditions determine success (Schedler \& Proeller, 2007). The Kehler Management System reflects these essential ideas and integrates research results and practical experience in a practice-oriented framework for a holistic municipal control and management system, including not only goal orientation and formal structure of the organizations, but also their culture. The KMS is particularly suitable for small and medium-sized municipalities since it provides understandable, low-threshold analysis tools for a quick check. On this basis, tailor-made measures can be developed to optimize the effectiveness and efficiency of administrative management.

The core of the KMS is an (open) list of success factors of municipal management, each of which is further concretized by questions/elements. The success factors are weighted differently: There are indispensable, important and complementary success factors. The success factors are not fixed, but can be exchanged, expanded and their weighting adjusted based on empirical studies. Of course, the KMS itself is not capable of learning, but it allows for a simple and flexible adaptation. With the aim of making For KMS to be easy to understand and manage in municipal practice, 36 success factors have been recorded to date, which have been condensed into six success clusters. On the other hand, 178 questions have been assigned to the success factors to enable a detailed analysis of the performance of a municipality in relation to the success factors.

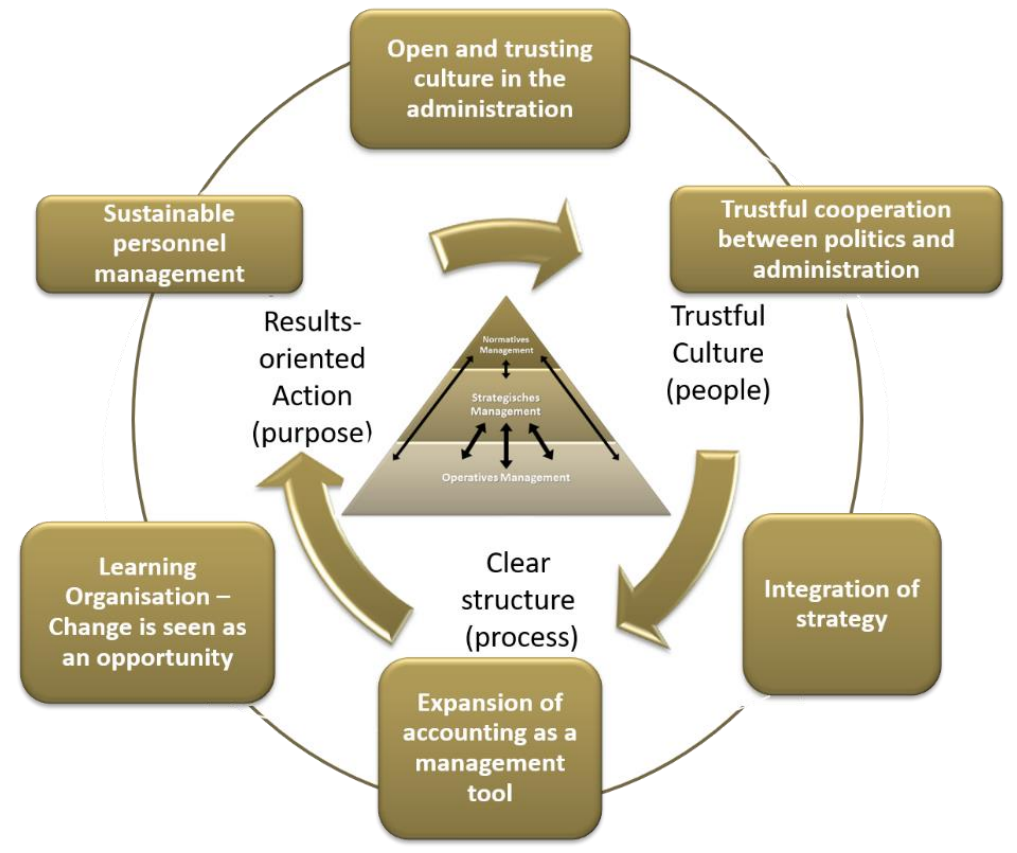

Fig. 1. Kehler Management System Cycle

Figure 1 illustrates the structure of the KMS. The pyramid shows that the three management levels (operational, strategic and normative management) are linked to optimal processes - shown by the arrows - in an organization. The processes are based on target-oriented actions, a trustful culture and clear process structures. On the outside, the six success clusters are shown as superordinate areas of the $K M S$.

Success cluster 1: Integration of strategy - Municipalities align their actions - ideally against the background of an individual mission statement - with a strategy. To do so, the following success factors must be addressed: 
Implementation of a broad-based mission statement development process (normative level), Development of an individual strategy for the municipality (strategic level); Operative actions are aligned with the strategy and are made transparent through targets and measures (operative level); Strategic planning is integrated into the steering cycle; Strategic planning is integrated into the budget; Contract management and the annual accounts; Strategic planning is the guiding principle for managing investments; Strategic planning is integrated into the core processes; Strategy, decisions, and implementation are linked together in a target-oriented manner; Strategically oriented organizational development; Strategic financial management forms the framework and opens scope; Municipal action is gradually geared to impact targets; Participation - involvement of third parties and so on.

Success cluster 2: Expansion of accounting as a management tool - This success cluster relates to the conversion to a modern accrual accounting and budget system, which considers resource consumption and output orientation. A stakeholder-oriented reporting system must be implemented that covers the information needs of managers and politicians in line with requirements:

Migration to a modern budget and accounting system; Implementation of a stakeholder-oriented reporting system; Formulation of meaningful impact, performance and financial targets, including appropriate key figures and indicators for an accurate measurement of the achievement of objectives; Management support through the expansion of an impact and results-oriented controlling system; All the processes are supported by efficient and user-friendly technology; Decentralization based on the principle of covering tasks, competence and responsibility, and so on.

Success cluster 3: A trustful cooperation between politics and administration - As mentioned, one characteristic of a good municipal management system is that it takes into account the complexity resulting from numerous actors with different views and motivations. The rationality of administrative management compared to political rationality is the typical example in this context and is therefore mapped out as a success cluster:

Good culture of trust and information; Politics and administration help each other and understand each other's role (political rationality versus rationality of administrative management); The wishes of politicians (political rationality) are considered through appropriate measures and so on.

Success cluster 4: Open and trusting culture within the administration - The leadership and cooperation culture within the administration is another success factor and is characterized by trust and passion and is open to change:

Managers are aware of their role and they act accordingly; Managers are enthusiastically committed to common targets; Regular confidence-building measures within the administration are a matter of course; Regularly informing employees about current developments in the administration and its environment; Employees and managers form successful teams focused on the jointly agreed targets and so on.

Success cluster 5: Sustainable human resources management - This success cluster focuses on sustainable human resources management, which is particularly evident in transparent and successful personnel selection, development and retention:

The personnel strategy supports the strategic orientation of the community; There is a personnel development concept based on this strategy, which enables the early development of core competencies; Employee appraisals are conducted regularly; Employees are regarded as the most valuable resource; A high level of employee satisfaction is aimed for and so on.

Success cluster 6: Learning organization - change is seen as an opportunity - The last success cluster deals with the 'learning system' that is characteristic of a good municipal management system. Changes in the administrative environment are recognized and used as opportunities for learning and improvement:

Continuous improvement processes are culturally implemented; Based on impulses from its internal and external environment, the city administration can identify necessary changes at an early stage and react quickly and appropriately; Changes are recognized as opportunities and used for early adaptation; Adaptation of habitual patterns to the new management culture and so on. 
In a case study on strategic management in the district of Lörrach, Germany, it was shown that these six clusters can be brought into a causal order (Kientz, 2012). The development of accrual accounting system into a fully functional control instrument within the framework of NHKR and the integration of the strategic perspective into the central control processes of the municipality (especially budget and output planning) can be regarded as fundamental objectives. They enable effective, economical and target-oriented management. Effects and impacts are what local government and politics ultimately want to achieve; however, resources are limited. This implies that not only target-oriented but also sustainable, consumption-oriented resource management is required. The four remaining clusters are of great importance to the success or failure of the NHKR reform process. With a culture of cooperation, personnel and change management, they describe structural and cultural conditions that increase the probability of professional management and consistent and sustainable target orientation of municipal action. In small to medium-sized municipalities, an individual culture develops based of tradition, personal relationships, mutual trust, and a sense of community. This is reflected in both administration and politics. The KMS takes this characteristic into account, by explicitly addressing trustful cooperation and internal administrative culture in two success clusters: open and trusting culture within the administration and trustful cooperation between politics and administration. Cultural aspects also play an important role in the success clusters learning organization and sustainable human resources management.

A summary of the KMS' three-layer approach - success clusters, success factors, subordinated questions - is illustrated in Table 1.

Table 1. KMS' three-layer approach

\begin{tabular}{|l|l|l|}
\hline Success cluster & Number of success factors & Number of questions \\
\hline Integration of strategy & 3 & 9 \\
\hline Expansion of accounting as a management tool & 5 & 39 \\
\hline $\begin{array}{l}\text { Trustful cooperation between politics and } \\
\text { administration }\end{array}$ & 13 & 58 \\
\hline Open and trusting culture within the administration & 6 & 26 \\
\hline Sustainable human resource management & 5 & 29 \\
\hline $\begin{array}{l}\text { Learning organization - change is seen as an } \\
\text { opportunity }\end{array}$ & 4 & 17 \\
\hline Sum & $\mathbf{3 6}$ & $\mathbf{1 7 8}$ \\
\hline
\end{tabular}

Small to medium-sized municipalities usually do not have sufficient resources to implement comprehensive approaches and frameworks for outcome assessment. This and the approaches' complexity discourage administrators and politicians. Here, the KMS offers a low-threshold service, as the success factors with their subordinate questions can be queried in a so-called Quick Check. Advisory support needed is low. The results are a first, initial analysis. This offers many small and medium-sized municipalities the opportunity to identify weaknesses and potential for improvement to initiate improvements in a targeted manner and depending on the available resources. The Quick Check can also be used to check at regular intervals without considerable effort whether and to what extent the desired improvements have been achieved. This has two positive consequences. Firstly, possible undesirable developments of the improvement process can be identified at an early stage. Secondly, stakeholder motivation can be increased if improvements achieved are identified and communicated.

The KMS currently addresses primarily the internal view by looking at the interplay between administration and politics, among other things. However, this is not sufficient for the successful development of a community. For this reason, the further development of the KMS will address an external view as opposed to the internal view. For this purpose, six success clusters are being developed, which address the demands of citizens, associations, local businesses, other state authorities and 
neighbouring municipalities, and the side of the investors. For the analysis of the clusters, subordinated questions will again be used to compare the services provided by the municipality with the requirements. The two views will be linked by a cause-and-effect chain that analyses different services in the form of products, projects and programs.

\section{Research results}

In 2015, the Kehl University of Applied Sciences carried out a survey covering the 115 municipalities and cities in Baden-Württemberg that had already converted their budget and accounting systems to the NKHR at that time and whose total population was less than 50,000 inhabitants (Böhmer \& Schwalb, 2016). The questionnaire was used to measure both the implementation status in the municipalities, the estimated relevance and weighting of the success factors of just over half of the success factors and subordinate questions currently recorded in the KMS. The response rate was $75 \%$.

Success cluster 1: Integration of strategy - 39\% of the municipalities and cities surveyed had or were developing a medium to long-term strategy with the Council. In addition to the larger cities, the small municipalities with less than 5,000 inhabitants proved to be particularly progressive in this respect. Among the reasons that led the majority of municipalities not (yet) to develop a strategy, disinterest on the part of the municipal council (30\%) and doubts on the part of the administrative management about the added value of a strategy (28\%) ranked in the top places. Of the chamberlains surveyed, $78 \%$ believed that strategic targets were 'indispensable' or 'important' for successful management. However, the assessment of the relevance of a strategy adopted and documented by the Council was strongly related to whether the municipality itself worked with strategic targets $(\gamma=0.44)$. This indicates that, as a rule, no disillusionment arises after the introduction of formal strategic planning.

Success cluster 2: Expansion of accounting as a management tool - In 2015, almost $2 / 3$ of respondents denied whether the budget explicitly states performance targets and the measures and resources to pursue them. The plausible assumption that the inclusion of performance targets in the budget is only a matter of time was not supported by the data $(\mathrm{r} \approx 0)$.

Success cluster 3: A trustful cooperation between politics and administration - Almost all respondents believed that the trust of the council in the administration, the reliability of the council, a cooperative and fact-oriented discussion culture in the committees and a clear division of responsibilities between politics and administration are 'important' or 'indispensable' for the successful management of a municipality. The quality of cooperation between politics and administration was already rated as good to very good in most of the municipalities surveyed in 2015. However, the perceived reliability of the municipal council and the perceived trust of the council in the administration tend to be rated lower with increasing municipal size, which is particularly noticeable in the decreasing proportion of extremely positive feedback. This could be explained by the information asymmetry between politics and administration, which increases with the size of the administration. It is also possible that the partypoliticization of local politics in the (larger) cities plays a role.

Success cluster 4: An open and trusting culture within the administration - According to the results, there hardly seem to be any municipalities in which cooperation between organizational units is a serious problem. Most respondents (61\%) said that cooperation was 'good' or 'very good'.

Success cluster 5: Sustainable human resources management - From the point of view of those surveyed, high employee satisfaction and personnel continuity were 'important' or 'indispensable' (92\% and $95 \%$ respectively) and decisive points in the changeover process. Against this background, it was sobering to note that more than $3 / 4$ of those surveyed believed that the administrative management should make more effort to ensure employee satisfaction (79\%), especially in smaller municipalities. 
Success cluster 6: Learning organization - change is seen as an opportunity - In the view of the respondents, the most important factor for the successful development of a municipality is that the top management actively and purposefully pushes ahead with planned changes. $61 \%$ consider this factor to be 'indispensable'; if one considers only those municipalities that are strategically managed, the proportion rises to $76 \%$. This finding should not come as a surprise, given that the implementation of the New Steering Model within the NKHR is a process of change. In addition to a pronounced information and communication policy - see success cluster 4 - the commitment of the management proves to be one of the central success factors of all organizational changes (Sirkin et al., 2005).

Conclusions for the practice of municipal management and its reform - In conjunction with the results of the survey, three explicit recommendations for a successful reform of local government, as defined by the NKHR, can be derived from the KMS:

1. Identification - the top management must stand behind the planned changes and actively represent and promote them.

2. Trust - trust is the 'lubricant' of good cooperation between the council and the administration.

3. Transparency - the employees must be informed to such an extent that they can understand and support the change decisions and processes.

The introduction of the NKHR was not only intended to change the style of accounting to the municipal accrual accounting system to improve municipal economic performance, but also to optimize municipal policy performance. To promote this goal, the KMS was introduced within a case study in the municipality of Ottersweier in 2017. This included an analysis of the current situation and a proposal for improvement tailored to individual needs for the further development of the municipality. When assessing an individual municipality, the survey is carried out by the actors of the municipality in selfassessment. The results are presented in a gap analysis. After discussing the results with the administration management, professors of the University of Applied Sciences Kehl as project coordinators develop an individual concept for the further development of the community. This includes tailor-made measures aimed at fulfilling the success factors and ultimately at the common good. To check the success of the implemented measures as well as all success factors, a new survey with the diagnostic tool should be carried out every 1 to 2 years.

As already mentioned, the success factors in KMS are divided into 3 categories: indispensable, important and complementary. When assessing an individual municipality, the relevance of these categories depends on the size of the municipality: small municipalities - up to 4,000 inhabitants, medium-sized municipalities - up to 10,000 inhabitants and large municipalities with more than 10,000 inhabitants. It is possible that a success factor has a different relevance for a small municipality than for a large municipality. Depending on the degree of implementation, these will then receive points that are weighted according to relevance.

The municipality of Ottersweier is in the region of Central Baden with 6,357 inhabitants (as of 31.12.2018). In the KMS classification, it is a medium-sized municipality. The mayor has overseen the administration since 1999. The organization has three subdivisions: Main office, accounting and real estate office as well as building office/building yard. At the time the KMS was introduced, Ottersweier had 18 municipal councils.

In 2017, the municipality of Ottersweier was the first pilot municipality to carry out an analysis with the KMS. In this first case study, the KMS and the diagnostic tool developed for it were to be tested for their practical suitability. Problems that arose during the first application of the diagnostic tool were solved and tested in the run up to the new survey.

Review of the first survey in the municipality of Ottersweier in 2017 - For a municipality to achieve meaningful results, it is advisable to use as many different perspectives (politicians, managers, employees, citizens, etc.) as possible. The municipality of Ottersweier decided in 2017 that all employees of the municipal administration and the building yard as well as the municipal councils should be included in the survey. The potential users were divided into the following 3 groups: local councils, employees and managers. The group of managers included the mayor, the heads of the offices and their deputies, resulting in a group of 9 users. The group of employees was assigned 30 persons. In 
addition, there were 18 municipal councils. In total, 57 potential users were thus available for the survey. The survey was carried out in paper in spring 2017. Results were anonymized within the various groups.

In 2017, it was decided that the 175 questions of the diagnostic tool should not be answered by all participants, but should be assigned to the groups that are expected to be able to answer the questions (at least by a majority). For the group of employees and the group of local councils, this assignment led to a reduction in the scope of the survey.

A brief explanation of the evaluation will be given here to be able to classify the results. If at least $80 \%$ of the maximum score is achieved, a cluster of success can be considered fulfilled and there is little or no need for action in this area in terms of KMS. The value is based on the existing evaluation systems and on the Pareto principle. Following the survey and the analysis of the actual situation, the results were evaluated to check whether there are weak points that are in need for action in terms of KMS. If this is the case, a project is designed and managed in the community, and supervised by professors from the University of Applied Sciences Kehl. If deficits are identified in the essential success clusters of culture ('politics and administration'; 'leadership and cooperation'), these success clusters must first be improved so that the potential of other success clusters can then be used. In the municipality of Ottersweier, good to very good results were achieved in the success clusters, with values between $67.5 \%$ and $89.5 \%$ of the maximum score when the diagnostic tool was used for the first time (Böhmer \& Zimmermann, 2018). In the totality of all the questions, $79.0 \%$ of the possible points were achieved in Ottersweier. The success clusters 'politics and administration' (89.5\%), 'strategy' (85.4\%) and 'information needs for accrual accounting' (80.6\%) can be considered fulfilled in the sense of the KMS approach. In these areas, there is little or no need for action. Only in the success clusters, 'Leadership and Cooperation' (67.5\%), 'Personnel Management' (74.0\%) and 'Changes' (74.8\%) did the municipality of Ottersweier fall just short of the target rating. Although in the latter success clusters more potential for improvement can be derived from the survey, good results were also achieved here. For the municipality, this means that its existing management already largely corresponds to a municipality oriented towards the common good and sustainable management in the sense of the KMS. After solving the few problem points, it can also have a certificate issued on request.

Due to the good results in the as-is analysis, there were only small opportunities for improvement in the community of Ottersweier, which were directly incorporated into a project. For example, the target value of at least $80 \%$ for the success cluster 'Sustainable Human Resources Management' was only just missed at $74 \%$. It was agreed that a corresponding bachelor's thesis would be written and supervised for the purpose of targeted optimization. A similar approach has been adopted for the other success clusters, where the degree of fulfilment was below $80 \%$. This means that existing potential for improvement in a community will be resolved, if possible, with the help of the students, via bachelor theses, study projects, seminar papers and so on.

A second survey was carried out in April and May 2019 with 55 participants from the council (18 members), management (5 persons) and employees (32 persons). Again, in 2019 Ottersweier reached good to very good results with values between $62.7 \%$ and $89.9 \%$ of the maximum number of points in the individual success clusters (Belz \& Böhmer, 2020). In the success clusters 'Personnel management', 'Change' and 'Leadership', 80\% could not be achieved. The values are still in a good range but offer more potential for improvement. At 78.8\% overall, the result of $79.0 \%$ from 2017 was repeated. The results of the individual success clusters are visualized using the following spider network diagram and compared with the results of the 2017 survey (results: 2017 blue; 2019 red). 


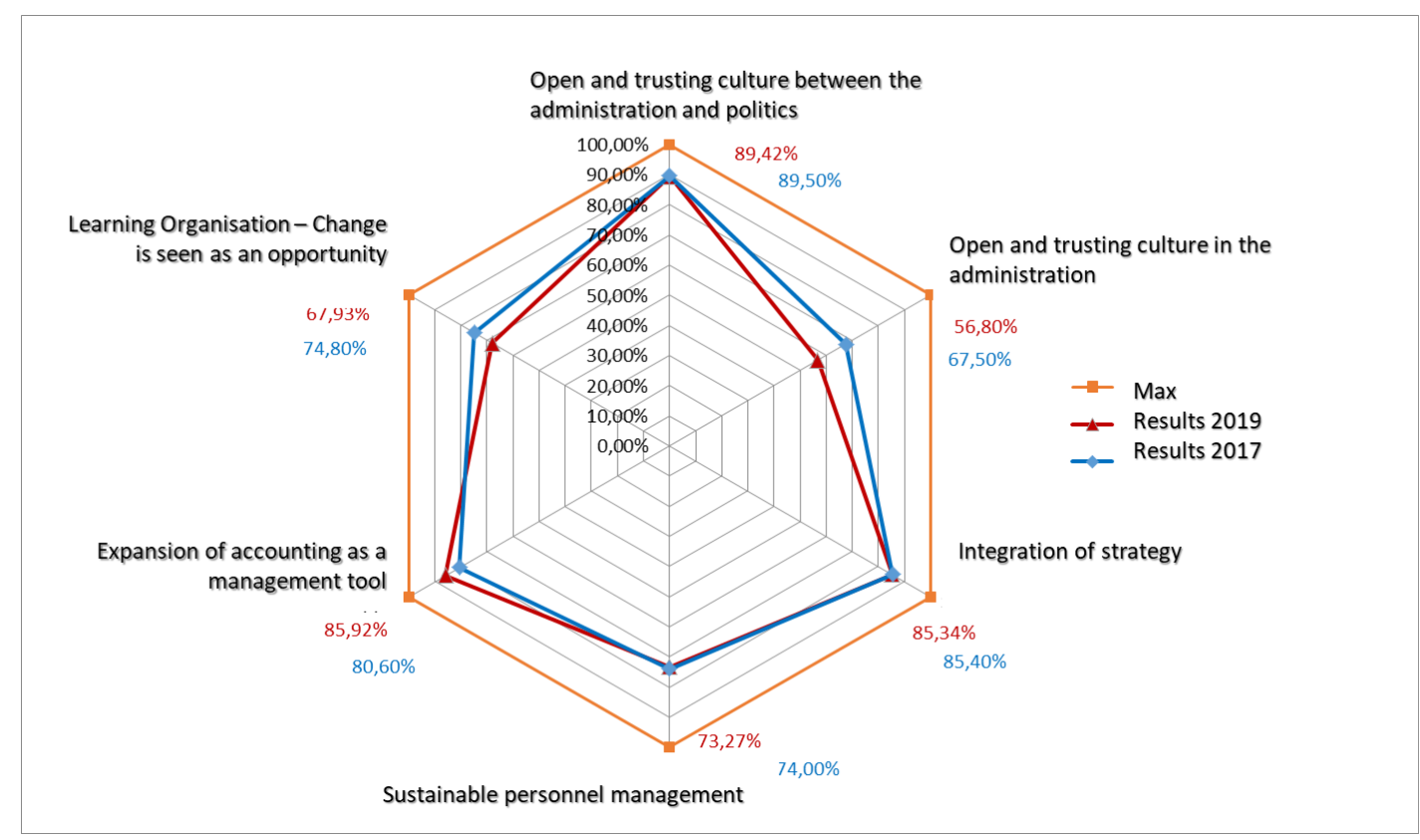

Fig. 2. Comparisons of two case studies in Ottersweier

When comparing the values of 2019 with the values of 2017, the municipality of Ottersweier reduced some very good to good results. While the success cluster 'Management Information' improved by almost 5 percentage points, the success clusters 'Politics and Administration', 'Strategy' and 'Human Resources Management' remained constant at the values already achieved in 2017. The success clusters 'Leadership' and 'Change' recorded a decline of 4.8 and 6.4 percentage points, respectively.

There is not a single success factor with a score of less than $50 \%$ of the score. On closer inspection, however, individual questions on the success factors scored significantly less than 50\%:

- Are there formulated personnel and management principles that describe the desired behaviour? $(34.4 \%)$

- Does my manager convey visions and can inspire for targets? (50.0\%)

- Are noticeable consequences drawn from the results of the employee interviews? (39.7\%)

- Is the daily work in the administration characterized by a noticeable team spirit, in which 'us' is preferred over 'me'? (40.5\%)

- Are the results of the appraisal interviews recorded in writing? (45.2\%)

- Are there transparent decision-making structures in which employee participation is firmly anchored? (40.9\%)

The greatest potential for improvement lies in the 'Leadership' success cluster. A comparison with the 2017 figures shows that this success cluster suffered a slump of 4.8 percentage points. For a differentiated analysis, the questions of the 'Leadership' success cluster were used, which were rated worst with less than 50\%:

Only $39.7 \%$ were able to answer the question 'Are noticeable consequences drawn from the results of the employee interviews and surveys?' with 'Yes.' Also, the question 'Are the results of the employee interview recorded in writing in order to achieve the targets?' could only be answered in the affirmative by $45.2 \%$. Employee interviews in which 'employees and managers talk about work tasks, workplace design, cooperation and development prospects' have not been held in the Ottersweier community to date. There are only annual talks as part of the performance evaluation.

As the question 'Is the appraisal interview an instrument firmly anchored in the municipality, the use of which is expressly demanded by the administrative management and the implementation of which is 
clearly regulated in a guideline?' was answered in the affirmative with $70 \%$, it can be assumed that the term 'appraisal interview' was misinterpreted by many of the survey participants and confused with the annual performance evaluation interviews. However, the results of the individual questions on the appraisal interview show that no or hardly noticeable consequences are drawn from interviews taking place, such as those on performance assessment, and that no results are recorded. This crushes motivation, which has a negative impact on the working atmosphere.

From the comments on the 'Leadership' success cluster, it must be concluded that many employees are frustrated. To improve communication and cooperation between the management and employee levels, the introduction of 'appraisal interviews' was suggested. The appraisal interview, which is to be held once a year between employees and management, is a solution-oriented development discussion about personal targets. These must be jointly formulated and recorded in writing in a protocol. It offers the opportunity to reach mutual agreements on work tasks, working environment, cooperation and leadership. Constructive criticism should be an opportunity for further development.

Since the appraisal interview can create clear structures, lead to target-oriented action and develop a culture of trust through communication and constructive exchange, the introduction of this management instrument is of great importance with regard to the optimization of the existing management system in Ottersweier. Not least because the municipality of Ottersweier has set itself the target of communication as an elementary success factor on a normative level. A prerequisite for successful employee appraisals is broad acceptance among the workforces. The implementation of the appraisal interviews must be prepared carefully and carried out sensitively. The Ottersweier community was therefore recommended to support the process by providing appropriate training for managers and, if necessary, employees.

The pilot project has shown that with the help of the KMS, a successful analysis of the status quo of a medium-sized municipality can be carried out. The municipality of Ottersweier was then able to submit a practical suggestion for improvement tailored to its needs. Since the municipality of Ottersweier, measured by the analysis of the KMS, is a successful municipality, works sustainably and is oriented towards the common good, it was awarded the KMS certificate as a pilot municipality for the first time.

\section{Final remarks and conclusions}

The introduction of the new NHKR is expected to fundamentally change municipal control, supported by the introduction of municipal accrual accounting and new product budgets. Although new information can be obtained through this new system, it is questionable how this information will be used in practice to make decisions to improve the performance of a municipality.

The KMS supports municipalities by providing a holistic, low-threshold approach to an as-is analysis that identifies areas for performance improvement. A three-layer-approach - success clusters, success factors, subordinate analysis questions - enables regular self-assessments with the diagnostic tool Quick Check. The result is an internal administration view of its performance. It can be compared with the opinions of the stakeholders of the respective municipality (citizens, associations, clubs, companies, etc.). For a more objective analysis of this external view, the KMS will be extended by a diagnostic tool such as the internal Quick Check.

Further case studies and surveys will be conducted to improve the comprehensibility and targeting of the individual questions per success factor by adjusting their weighting. A database for storing causeeffect chains will be implemented. This historical data can be used as a basis both for predicting future events and for planning projects to improve performance.

The two case studies of Ottersweiher have shown that KMS already provides a useful framework for small to medium sized communities through self-assessment, which identifies both the occurrence of improvements and newly emerging problems through repeated application. 


\section{References}

Belz, C. \& Böhmer, R (2020). Anwendung des Kehler Management-Systems $\bigodot$ am Beispiel der Gemeinde Ottersweier. In: Böhmer, R, Kegelmann, J. \& /Kientz J (eds) Rechnungswesen und Controlling - Das Steuerungshandbuch für Kommunen, accepted for publication in 2020 (in German).

Böhmer, R. \& Zimmermann, S. (2018). Analyse der Gemeinde Ottersweier mithilfe des Kehler ManagementSystems. In: Böhmer, R, Kegelmann, J. \& Kientz J. (eds) Rechnungswesen und Controlling - Das Steuerungshandbuch für Kommunen, 18(8), 471-504 (in German).

Böhmer, R. \& Schwalb, B. (2016). Erfolgsfaktoren kommunaler Steuerung: Ergebnisse einer Umfrage unter Kommunen in Baden-Württemberg. In: Böhmer, R, Kegelmann, J. \& /Kientz J (eds) Rechnungswesen und Controlling - Das Steuerungshandbuch für Kommunen, 16(8), 1407-1432 (in German).

Cordella, A. \& Bonina, C. (2012). A public value perspective for ICT enabled public sector reforms: a theoretical reflection. Government Information Quarterly, 29(4), 512-520.

Davis, S. \& Albright, T. (2004). An investigation of the effect of Balanced Scorecard implementation on financial performance. Management Accounting Research, 15(2), 135-153.

Fischer, E. \& Lasar, A. (2014). Steuerungswirkungen des Neuen öffentlichen Haushalts- und Rechnungswesens. Verwaltung und Management, 20(3), 130-134 (in German).

Fryer, K., Anthony, J. \& Ogden, S. (2009). Performance management in the public sector. International Journal of Public Sector Management, 22(6), 478-498.

Hood, C. (1991). A public management for all seasons? Public Administration, 69(1), 3-19.

Jessa, F. \& Uys, F. (2013). A normative approach to organisational performance management (OPM) in municipalities. Administratio Publica, 21(1), 102-126.

Kaplan, R. \& David, P. (1992). The balanced scorecard - Measures that drive performance. Harvard Business Review, 70 (1), 71-79.

Leach, S. \& Lowndes, V. (2004). Understanding Local Political Leadership: Constitutions, Contexts and Capabilities. Local Government Studies, 30(4), 557-575.

Malina, M., Nørreklit, H. \& Selto, F. (2007). Relations among Measures, Climate of Control and Performance Measurement Models. Contemporary Accounting Research, 24(3), 935-982.

Manville, G. (2007). Implementing a balanced scorecard framework in a not-for-profit SME. International Journal of Productivity and Performance Management, 56(2), 162-169.

Moullin, M. (2006). The design of an alternative balanced scorecard framework for public and voluntary organizations. Perspectives on Performance, 5(1), 10-12.

Moullin, M. (2017). Improving and evaluating performance with the Public Sector Scorecard. International Journal of Productivity and Performance Management, 66(4), 442-458.

Nørreklit, H. (2003). The Balanced Scorecard: What is the Score? A Rhetorical Analysis of the Balanced Scorecard. Accounting, Organizations and Society, 28(6), 591-619.

Sirkin, H.L., Keenan, P. \& Jackson, A. (2005) The Hard Side of Change Management. Harvard Business Review, 83(10), 108-118.

Yui, M. \& Gregory, R. (2018) Quakes and Aftershocks - organisational restructuring in the New Zealand state sector, 1960-2017. Policy Quarterly, 14 (3), 25-32.

Best, E. (1997). Capacities for Regional Integration: a Conceptual Framework for Comparative Analysis. In Hosli, M. \& Saether, A. (eds.): Free trade agreements and customs unions. Experiences, challenges and constraints. Brussels \& Maastricht: European Commission TACIS \& EIPA, pp. 51-78.

Boston J., Martin, J., Pallot, J., \& Walsh, P. (1996). Public management: The New Zealand model. Oxford: Oxford University Press.

Johari, J.C. (2001): Comparative Politics. New York: Sterling Publishers.

Moore, M. H. (1995). Creating public value: Strategic management in government. Cambridge, MA: Harvard University Press.

Schedler, K. \& Proeller, I. (2007): Cultural Aspects of Public Management Reform. Amsterdam: Elsevier. 
Brignall, S. (2002). The unbalanced scorecard: a social and environmental critique. In: Neely, A., Walters, A., \& Austin, R. (eds) PMA conference proceedings-performance measurement and management 2002: Research and action: cranfield school of management (pp. 85-92). Boston, MA: Performance Management Association (PMA).

Bukh, P. \& Malmi, T. (2005). Re-examining the Cause-and-effect Principle of the Balanced Scorecard. Aarhus School of Business. 1-27

Cannon, P. \& Fry, T. (1992). Performance measurement in the public sector, World Bank Working Paper Number $17572,1992 / 07 / 09$

Banner, G. (2005). Führung und Reform. Revised version of a lecture given at the University of Kassel on 22 October 2005 (retrieved from http://www.mpa.unikassel.de/media/ Banner.pdf) (in German).

Boston J. (2013). The quest for the good society: Economics, ethics and public policy - a seminar at the New Zealand Treasury (retrieved from https://apo.org.au/node/35809)

Kientz, J. (2012). Integration der strategischen Planung in die Haushaltsplanung einer Kommune - dargestellt am Beispiel des Landkreises Lörrach. PhD thesis at the University of Kassel (in German). 